\title{
Effect of Extreme Hypercapnia on Hypoxic-Ischemic Brain Damage in the Immature Rat
}

\author{
ROBERT C. VANNUCCI, JAVAD TOWFIGHI, \\ ROBERT M. BRUCKLACHER, AND SUSAN J. VANNUCCI \\ Departments of Pediatrics (Pediatric Neurology) [R.C.V., R.M.B., S.J.V.] and Pathology (Neuropathology) \\ [J.T.], The Pennsylvania State University College of Medicine, Penn State Milton S. Hershey Medical \\ Center, Hershey, Pennsylvania 17033-0850, U.S.A.
}

\begin{abstract}
TBST
To ascertain the effect of extreme hypercapnia on perinatal
hypoxic-ischemic brain damage, 7 -d-postnatal rats were exposed
to unilateral common carotid artery occlusion followed by hyp-
oxia with $8 \%$ oxygen combined with 3,12 , or $15 \%$ carbon
dioxide $\left(\mathrm{CO}_{2}\right)$ for $2 \mathrm{~h}$ at $37^{\circ} \mathrm{C}$. Survivors underwent neuropatho-
logic examination at $30 \mathrm{~d}$ of postnatal age, and their brains were
characterized as follows: $0=$ normal; $1=$ mild atrophy; $2=$
moderate atrophy; $3=$ cystic infarct with external dimensions
$<3$ mm; and $4=$ cystic infarct with external dimensions $>3$ mm.
The width of the cerebral hemisphere ipsilateral to the carotid
artery occlusion also was determined on a posterior coronal
section and compared with that of the contralateral hemisphere to
ascertain the severity of cerebral atrophy/cavitation. $\mathrm{CO}_{2}$ ten-
sions averaged $5.08,11.1$, and $13.2 \mathrm{kPa}$ in the 3,12 , and $15 \%$
$\mathrm{CO}_{2}$-exposed animals, respectively, during hypoxia-ischemia
$(\mathrm{HI})$. Neuropathologic results showed that immature rats exposed
to 3 and $12 \% \mathrm{CO}{ }_{2}$ had similar severities of brain damage. In
contrast, rat pups exposed to $\mathrm{HI}$ combined with $15 \% \mathrm{CO}_{2}$ were
significantly more brain damaged than littermates exposed to $3 \%$
$\mathrm{CO}_{2}$. Specifically, eight of 14 animals exposed to $15 \% \mathrm{CO}$
showed cystic infarcts (grades 3 and 4 ), whereas none of 14
\end{abstract}
In a previous investigation, we demonstrated that hypocapnia aggravates and mild hypercapnia protects the immature rat from hypoxic-ischemic brain damage (1). Specifically, it was determined that immature rats subjected to HI without concurrent $\mathrm{CO}_{2}$ exposure exhibit $\mathrm{PCO}_{2}$ approximating $3.5 \mathrm{kPa}(26 \mathrm{~mm}$ $\mathrm{Hg}$ ), whereas rat pups exposed to 3 and $6 \% \mathrm{CO}_{2}$ during $\mathrm{HI}$ exhibit $\mathrm{PCO}_{2}$ values of $5.1 \mathrm{kPa}(38 \mathrm{~mm} \mathrm{Hg})$ and $7.3 \mathrm{kPa}(55 \mathrm{~mm}$ $\mathrm{Hg}$ ), respectively. Neuropathologic analysis at $30 \mathrm{~d}$ of postnatal age in rats previously exposed to HI with varying concen-

Received October 26, 2000; accepted February 20, 2001.

Correspondence: Robert C. Vannucci, M.D., Division of Pediatric Neurology (MC H085), Penn State Milton S. Hershey Medical Center, P.O. Box 850, Hershey, PA 17033-0850; e-mail: rvannucci@psu.edu

Supported by Program Project HD-30704 from The National Institute of Child Health and Human Development. littermates exposed to $3 \% \mathrm{CO}_{2}$ developed cystic infarcts $(p<$ $0.01)$. Analyses of coronal width ratios at each $\mathrm{CO}_{2}$ exposure provided results comparable with those of the gross neuropathology scores. Cerebral blood flow (CBF), measured at $90 \mathrm{~min}$ of $\mathrm{HI}$, was lowest in those immature rats exposed to $15 \% \mathrm{CO}_{2}$ compared with control $(p=0.04)$, with higher values in those rat pups exposed to 3 and $12 \% \mathrm{CO}_{2}$. The findings indicate that 7 -d-postnatal rats exposed to $\mathrm{HI}$ with superimposed $12 \% \mathrm{CO}_{2}$ are neither less nor more brain damaged than littermates exposed to $3 \% \mathrm{CO}_{2}$ (normocapnia). In contrast, animals exposed to $15 \%$ $\mathrm{CO}_{2}$ are the most brain damaged of the three groups. Presumably, extreme hypercapnia produces more severe cardiovascular depression than is seen in animals subjected to lesser degrees of hypercapnia; the cardiovascular depression, in turn, leads to greater cerebral ischemia and ultimate brain damage. (Pediatr Res 49: 799-803, 2001)
CBF, cerebral blood flow
Abbreviations
HI, hypoxia-ischemia

trations of $\mathrm{CO}_{2}$ at $7 \mathrm{~d}$ of postnatal age revealed that the hypocapnic animals show the worst brain damage, whereas the hypercapnic show the least brain injury. The rationale for these studies pertains to clinical investigations suggesting that premature infants who require mechanical ventilation to prevent or minimize hypoxemia arising from respiratory distress syndrome are at increased risk for the development of periventricular leukomalacia if hypocapnia occurs during the course of respiratory management $(2-4)$. What was not ascertained by these studies is the extent to which severe hypercapnia with $\mathrm{CO}_{2}$ tensions $>10.4 \mathrm{kPa}(80 \mathrm{~mm} \mathrm{Hg})$ is protective or deleterious to the immature brain. Accordingly, we conducted experiments to ascertain the effect of varying concentrations of $\mathrm{CO}_{2}$ on the neuropathologic outcome of immature rats subjected to cerebral HI. 


\section{METHODS}

Dated, pregnant Sprague-Dawley rats were purchased from a commercial breeder (Charles River Laboratories, Wilmington, MA, U.S.A.) and housed within individual cages. Offspring, delivered vaginally, were reduced to 10 per litter at birth and were reared with their dams until time of experimentation at $7 \mathrm{~d}$ of postnatal age.

Induction of cerebral HI. To produce brain damage caused by cerebral HI, 7-d-postnatal rats were anesthetized with halothane (4\% induction; $1.0-1.5 \%$ maintenance; $30 \% \mathrm{O}_{2}$; balance nitrous oxide). Under anesthesia, the midline of the neck was incised in the longitudinal plane, and the right common carotid artery was identified and separated from contiguous structures. The artery then was permanently ligated with 4-0 surgical silk, and the wound was sutured. Upon recovery from anesthesia, the animals were returned to their dams for 3-4 h. Thereafter, they were placed in 500-mL airtight jars partially submerged in a $37^{\circ} \mathrm{C}$ water bath to maintain a constant thermal environment $\left(35^{\circ} \mathrm{C}\right)$. A humidified gas mixture of $8 \% \mathrm{O}_{2}$ and balance nitrogen combined with a specific concentration of $\mathrm{CO}_{2}$ was delivered into the jars via inlet and outlet portals at an approximate flow rate of $100 \mathrm{~mL} / \mathrm{min}$. The $\mathrm{CO}_{2}$ concentrations were 3,12 , or $15 \%$ of the gas mixture. The rat pups were exposed to the gas mixture for $2 \mathrm{~h}$, after which they were allowed to recover for $15 \mathrm{~min}$ in open jars in the water bath. Thereafter, the animals were returned to their dams until $30 \mathrm{~d}$ of postnatal age, at which time they were killed for neuropathologic assessment (see below). The combination of unilateral common carotid artery occlusion and systemic hypoxia with $8 \% \mathrm{O}_{2}$ is known to produce brain damage in the form of selective neuronal death or infarction predominantly of the cerebral hemisphere ipsilateral to the arterial ligation $(5,6)$.

Neuropathologic analysis. At $30 \mathrm{~d}$ postnatal ( $23 \mathrm{~d}$ of recovery), all animals were injected s.c. with a lethal dose of pentobarbital $(100 \mathrm{mg} / \mathrm{kg})$; their brains were rapidly removed from their skulls and placed in solutions of formaldehyde, acetic acid, and methanol (FAM; 1:1:8). Two observers, blinded to the experimental manipulation, graded the presence and extent of damage on uncut brains in each animal. Individual brains were assigned to one of five categories as previously described (1): grade $0=$ normal; grade $1=$ mild brain atrophy; grade 2 = moderate brain atrophy; grade $3=$ atrophy with cystic infarct $<3 \mathrm{~mm}$; and grade $4=$ atrophy with cystic infarct $>3 \mathrm{~mm}$. Mild atrophy included those brains in which the posterior diameter of the ipsilateral cerebral hemisphere was up to $25 \%$ less than that of the contralateral hemisphere. Moderate atrophy included those brains in which the posterior diameter of the ipsilateral hemisphere was $25-50 \%$ less than that of the contralateral hemisphere but was short of cystic infarction.

Morphometric evaluation of the severity of damage within each brain also was determined based on the degree of shrinkage of the affected cerebral hemisphere. Individual brains were transected in the coronal plane at the mid-infundibular level, and the diameter (width) of each cerebral hemisphere was determined, excluding the lateral ventricle, choroid plexus, and any cystic area. The ratio of the width of the damaged (ipsi- lateral) cerebral hemisphere to that of the contralateral hemisphere then was calculated. We previously have demonstrated that the contralateral cerebral hemisphere can be used as an internal control, the size of which is comparable to that of an age-matched brain not subjected to unilateral cerebral HI (7).

Blood oxygen, acid-base, and biochemical analyses. In separate experiments, 7-d-postnatal rats that previously underwent carotid artery ligation were exposed to humidified gas mixtures containing $8 \% \mathrm{O}_{2}$ and variable concentrations of $\mathrm{CO}_{2}$, as described above. These animals were not placed in airtight jars; instead, each rat pup was gently positioned headfirst into the barrel of a $20-\mathrm{mL}$ plastic syringe (8). The narrow anterior opening of the syringe was connected via polyethylene tubing to the gas tank, whereas the larger posterior opening remained unoccluded. A microthermister probe was positioned adjacent to the torso of each rat to maintain a constant ambient environment of $35^{\circ} \mathrm{C}$ by the use of a servo-controlled heating lamp positioned $2^{\prime}$ directly above the syringe. An ambient temperature of $35^{\circ} \mathrm{C}$ is equivalent to that obtained in airtight jars when animals are exposed to $\mathrm{HI}$ in this procedure. The animals were exposed to hypoxia for either 1 or $2 \mathrm{~h}$, at which time their torsos were slowly withdrawn from the posterior end of the barrel to allow decapitation as the animal continued to inhale the gas mixture. Blood (approximately $0.1 \mathrm{~mL}$ ) was immediately collected from the severed neck vessels for analysis of $\mathrm{pO}_{2}, \mathrm{pCO}_{2}$, and $\mathrm{pH}$ on a micro-gas analyzer (Model ABL-30, Radiometer America, Inc., Westlake, OH, U.S.A.). Blood also was collected and plasma separated for determination of glucose concentration on a micro-glucose analyzer (Glucostat, Beckman Instruments, Inc., Fullerton, CA, U.S.A.). Finally, an aliquot of whole blood $(0.02 \mathrm{~mL})$ was diluted $1: 10$ in $0.5 \mathrm{M}$ perchloric acid for later determination of blood lactate concentration (9).

Measurement of $C B F$. CBF was measured in carotid arteryligated rat pups during the course of $\mathrm{HI}$ using a modification of the indicator fractionation technique, as previously described (10). Specifically, at $90 \mathrm{~min}$ of $\mathrm{HI}$, rat pups exposed to 3,12 , or $15 \% \mathrm{CO}_{2}$ were injected s.c. with $5 \mu \mathrm{Ci}$ of iodo- $\left[{ }^{14} \mathrm{C}\right]-$ antipyrine (DuPont-NEN, Boston, MA, U.S.A.). The injection was made into the back of the rat, approximately in the midline. Precisely $1 \mathrm{~min}$ after the injection, each animal was decapitated, and arterialized blood was collected from the severed neck vessels into a heparinized glass capillary tube. Ten $\mu \mathrm{L}$ of blood pipetted from the capillary tube were added to a scintillation vial containing $1.0 \mathrm{~mL}$ of Soluene-350 (United Technologies Packard, Downers Grove, IL, U.S.A.). After the solution was shaken overnight in a mechanical shaker, it was combined with $9.0 \mathrm{~mL}$ of Dimilume-30 (United Technologies Packard). Samples were then counted on a Beckman LS-350 liquid scintillation counter (Beckman Instruments, Fullerton, CA, U.S.A.). The brain of each rat pup was removed from its skull, and a small specimen (approximately $50 \mathrm{mg}$ ) of the right cerebral hemisphere in the distribution of the middle cerebral artery was removed and placed in a preweighed scintillation vial. After reweighing the vial to ascertain the weight of the brain tissue specimen, $1.0 \mathrm{~mL}$ of Soluene-350 was added to the vial. After mixing overnight, the solution was 
combined with $9.0 \mathrm{~mL}$ of Dimilume-30 and isotopically counted.

$\mathrm{CBF}$ was calculated from the concentration of the iodo$\left[{ }^{14} \mathrm{C}\right]$-antipyrine tracer in the blood and brain tissue specimen at $1 \mathrm{~min}$, assuming linearity in the input function from 0 to 1 (10). The brain:blood partition coefficient was assumed to equal 0.94 (11).

Statistical analysis. Statistical analysis of the data included the $t$ test and analysis of variance of a Bonferroni correction for multiple comparisons of means, where appropriate.

Institutional approval. The experiments described herein were reviewed by the Animal Care and Use Committee of the Milton S. Hershey Medical Center, Pennsylvania State University, and approved on May 21, 1998.

\section{RESULTS}

Results pertaining to the neuropathologic analysis of immature rats exposed to cerebral $\mathrm{HI}$ inhaling either 12 or $15 \% \mathrm{CO}_{2}$ were compared with littermates breathing 3\% $\mathrm{CO}_{2}$. We previously demonstrated that rat pups exposed to $3 \% \mathrm{CO}_{2}$ during $\mathrm{HI}$ are normocapnic during the insult (1) (see below). Our initial experiment was conducted on 317 -d-postnatal rats subjected to $2 \mathrm{~h}$ of $\mathrm{HI}$ combined with either 3 or $12 \% \mathrm{CO}_{2}$ (Fig. 1). Neuropathologic assessment at $30 \mathrm{~d}$ of age revealed no significant difference in the extent of brain damage between the two groups $(p=0.18)$. Analysis of the diameters (widths) of the damaged (ipsilateral) cerebral hemispheres compared with respective contralateral hemispheres provided results nearly identical to those obtained upon visual inspection of the brains. The ipsilateral/contralateral width ratio of the rat pups exposed to 3 and $12 \% \mathrm{CO}_{2}$ averaged 0.85 and 0.86 , respectively $(p=0.44)$.

Immature rats subjected to $\mathrm{HI}$ combined with $15 \% \mathrm{CO}_{2}$ were significantly more brain damaged than littermates exposed to

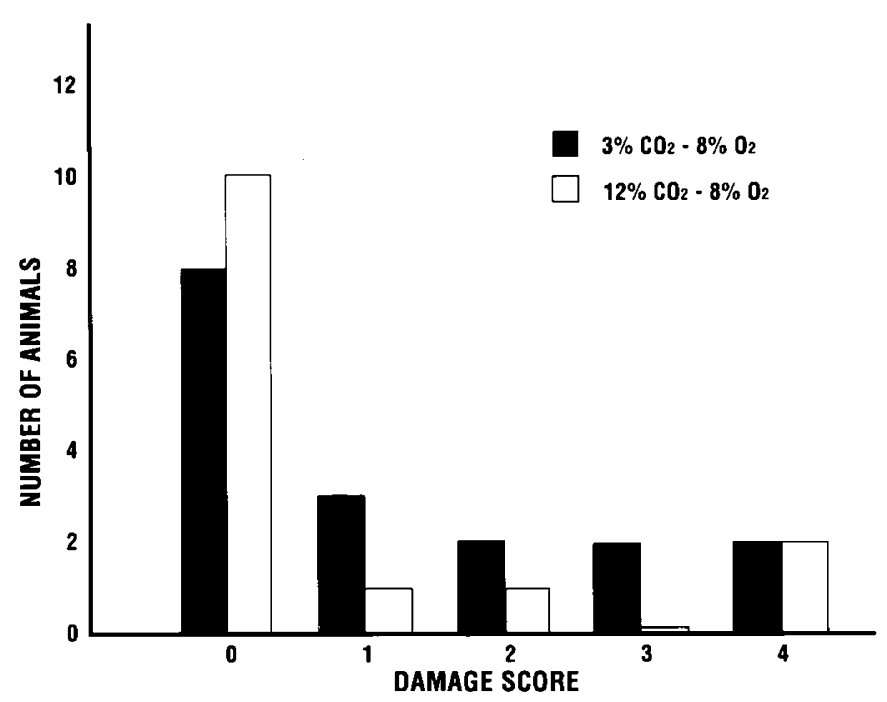

Figure 1. Severity of brain damage in rats previously subjected to cerebral HI with supplemental $\mathrm{CO}_{2}$ inhalation. Rats $7 \mathrm{~d}$ postnatal underwent unilateral carotid artery ligation followed by inhalation of either 3 or $12 \% \mathrm{CO}_{2}, 8 \% \mathrm{O}_{2}$, and balance nitrogen, after which they were returned to their dams until $30 \mathrm{~d}$ of postnatal age. The extent of brain damage in each animal was determined as described in "Methods."
$3 \% \mathrm{CO}_{2}$ (Fig. 2). Specifically, eight of $1415 \%-\mathrm{CO}_{2}$-exposed animals showed atrophy with cystic cavitation at $30 \mathrm{~d}$ of age, whereas none of 14 littermates exposed to $3 \% \mathrm{CO}_{2}$ showed grades 3 and 4 damage $(p<0.01)$. The ipsilateral/contralateral width ratio of the $15 \%-\mathrm{CO}_{2}$-exposed rat pups averaged 0.70 compared with a ratio of 0.91 in the $3 \%-\mathrm{CO}_{2}$-exposed littermates $(p=0.02)$.

In conclusion, 7-d-postnatal rats exposed to HI with superimposed $12 \% \mathrm{CO}_{2}$ were neither less nor more brain damaged than littermates exposed to $3 \% \mathrm{CO}_{2}$. In contrast, animals exposed to $15 \% \mathrm{CO}_{2}$ were the most brain damaged of the three groups.

Blood $\mathrm{O}_{2}$ and acid-base status was determined in 7-d-old carotid artery-ligated rats exposed to systemic hypoxia with supplemental $\mathrm{CO}_{2}$ (Table 1). $\mathrm{HI}$ with $3 \% \mathrm{CO}_{2}$ maintained normocapnia, and $\mathrm{pH}$ was unchanged from control, owing to an absence of metabolic acidemia. Inhalation of 12 and 15\% $\mathrm{CO}_{2}$ caused progressively greater hypercapnia, which despite the development of a metabolic alkalemia was associated with decreases in blood $\mathrm{pH}$.

$\mathrm{CO}_{2}$ exposure had a dramatic effect on blood lactate, such that high concentrations completely blunted any increase in the metabolite during HI, in contrast to lactate levels approximating $4 \mathrm{mmol} / \mathrm{L}$ in the normocapnic group (Fig. 3). $\mathrm{CO}_{2}$ inhalation at any level had a minimal effect on plasma glucose concentration (Fig. 3).

Data pertaining to $\mathrm{CBF}$ during $\mathrm{HI}$ are shown in Fig. 4. Control CBF averaged $40 \mathrm{~mL} / 100 \mathrm{~g} / \mathrm{min}$, a value similar to that previously reported for 7-d-postnatal rats (11). CBF, measured at $90 \mathrm{~min}$ of $\mathrm{HI}$, was lowest in those animals exposed to $15 \%$ $\mathrm{CO}_{2}$, compared with control $(p=0.04)$. $\mathrm{CBF}$ values were higher in those rat pups exposed to 3 and $12 \% \mathrm{CO}_{2}$, in which the values were similar and not significantly different from control.

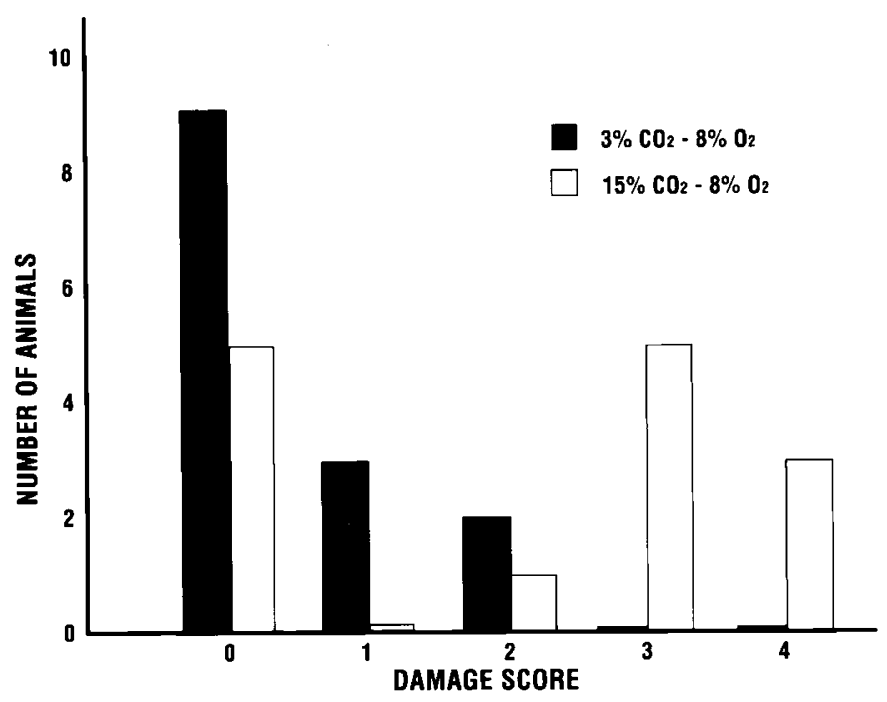

Figure 2. Severity of brain damage in rats previously subjected to cerebral $\mathrm{HI}$ with supplemental $\mathrm{CO}_{2}$ inhalation. Rats $7 \mathrm{~d}$ postnatal underwent unilateral carotid artery ligation followed by inhalation of either 3 or $15 \% \mathrm{CO}_{2}, 8 \% \mathrm{O}_{2}$, and balance nitrogen, after which they were returned to their dams until $30 \mathrm{~d}$ of postnatal age. The extent of brain damage in each animal was determined as described in "Methods." 
Table 1. Blood oxygen and acid-base status of immature rats exposed to hypercapnic cerebral hypoxia-ischemia

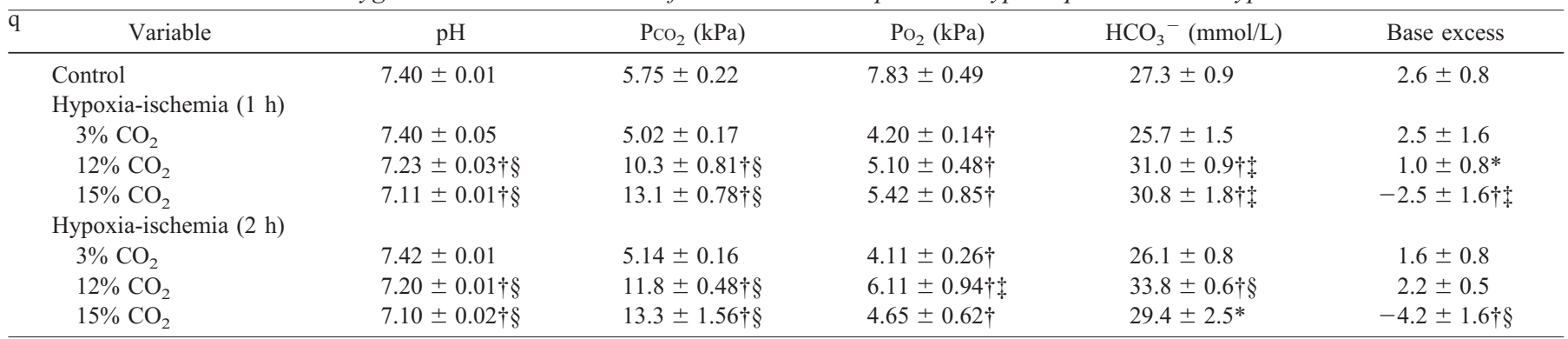

Values represent means \pm SEM of five to six animals in each group.

Control immature rats were exposed to neither hypercapnia nor hypoxia-ischemia.

$* p<0.05 ; \dagger p<0.001$ compared to control; $\$ p<0.05 ; \S p<0.001$ compared to $3 \% \mathrm{CO}_{2}$ at same interval of hypoxia-ischemia.
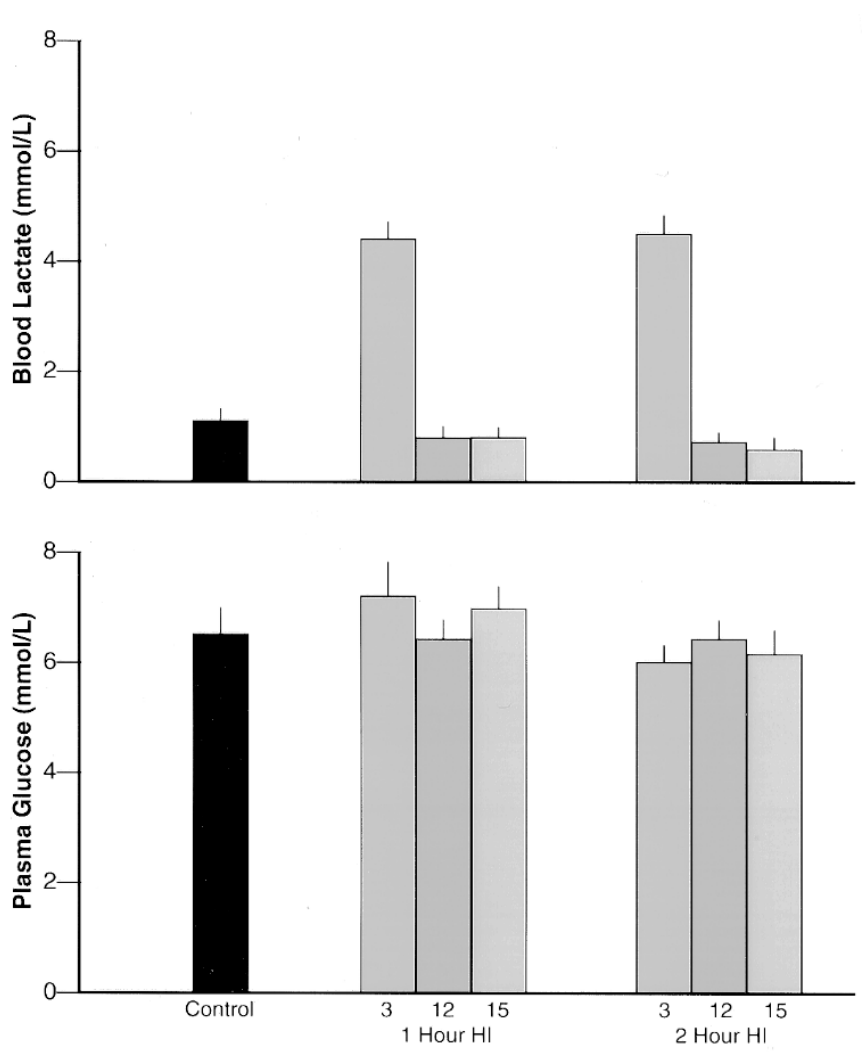

Percent Carbon Dioxide Inhalation

Figure 3. Plasma glucose and blood lactate concentrations in immature rats exposed to $\mathrm{HI}$ with supplemental $\mathrm{CO}_{2}$ inhalation. Control animals were not exposed to $\mathrm{HI}$ or hypercapnia. Bars represent mean concentrations of five to six animals; vertical lines denote \pm 1 SEM.

\section{DISCUSSION}

The primary objective of the present investigation was to study the effect of extreme hypercapnia on perinatal hypoxicischemic brain damage. To accomplish our goal, we exposed immature rats to $\mathrm{CO}_{2}$ concentrations that were expected to cause hypercapnia in the range of $10.4-13.0 \mathrm{kPa}(80-100 \mathrm{~mm}$ $\mathrm{Hg}$ ). The data show that hypercapnia in the $10 \mathrm{kPa}$ range neither protects nor aggravates perinatal hypoxic-ischemic brain damage compared with normocapnia, whereas hypercapnia in the range of $13 \mathrm{kPa}$ clearly is deleterious.

In a previous series of experiments, we demonstrated that normocapnic cerebral $\mathrm{HI}$ in the immature rat is associated with

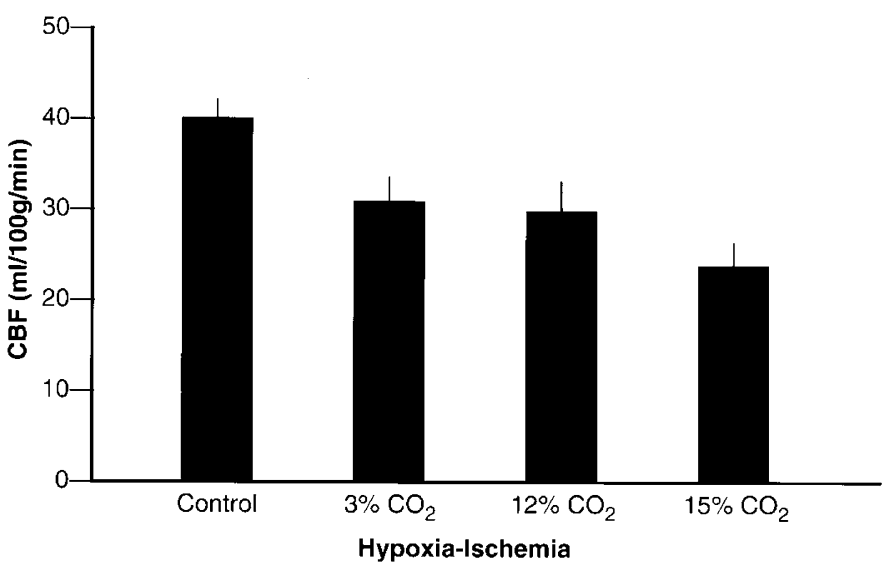

Figure 4. $\mathrm{CBF}$ during $\mathrm{HI}$ in immature rats exposed to varying concentrations of $\mathrm{CO}_{2}$. $\mathrm{CBF}$ measurements were obtained from the cerebral hemisphere ipsilateral to the common carotid artery occlusion at $90 \mathrm{~min}$ of HI. Bars represent mean concentrations of six to eight animals; vertical lines denote \pm 1 SEM.

less severe brain damage than seen in hypocapnic cerebral HI. Furthermore, mild hypercapnia in the range of $6.5-9.1 \mathrm{kPa}$ $(50-70 \mathrm{~mm} \mathrm{Hg})$ is more protective to the immature brain subjected to HI than normocapnia (1). Combining these previously published data with those presented here indicates that $\mathrm{CO}_{2}$ tensions during perinatal cerebral $\mathrm{HI}$ dramatically influences the severity of the ultimate brain damage (Fig. 5). Specifically, hypocapnia and severe hypercapnia accentuates hypoxic-ischemic brain damage, whereas mild hypercapnia is protective. Furthermore, there appears to be a very narrow window of mild hypercapnia that is protective to the immature brain subjected to HI.

In previous experiments published in this journal, we studied the $\mathrm{CBF}$ and metabolic alterations that occur in the immature rat during cerebral $\mathrm{HI}$ with superimposed hypocapnia $(0 \%$ $\left.\mathrm{CO}_{2}\right)$, normocapnia $\left(3 \% \mathrm{CO}_{2}\right)$, and mild hypercapnia $(6 \%$ $\mathrm{CO}_{2}$ ) (12). CBF during $\mathrm{HI}$ was better preserved in the normocapmic and hypercapnic rat pups; these animals also exhibited a stimulation of cerebral glucose utilization. Brain glucose concentrations were higher and lactate was lower in the normocapnic and hypercapnic animals, indicating that glucose was consumed oxidatively in these groups rather than by anaerobic glycolysis, as apparently occurred in the hypocapnic animals. ATP and phosphocreatine were better preserved in the normocapnic and hypercapnic rats compared with the hypocapnic animals. Cerebrospinal fluid glutamate, as a reflection 


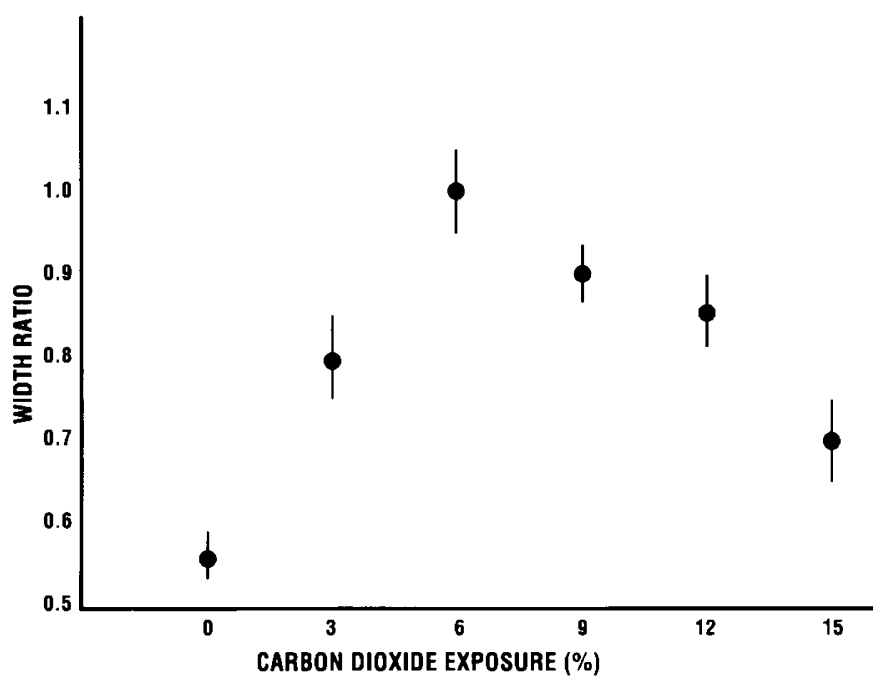

Figure 5. Brain ipsilateral/contralateral width ratios of rats previously subjected to $\mathrm{HI}$ with or without supplemental $\mathrm{CO}_{2}$ inhalation. Circles represent means; vertical lines denote \pm 1 SEM. Values for 0,6 , and $9 \% \mathrm{CO}_{2}$ exposure were derived from data of Vannucci et al. (1); values for 3, 12, and $15 \% \mathrm{CO}_{2}$ exposure were derived from present data. The lower the width ratio, the greater the damage to the ipsilateral cerebral hemisphere.

of the brain extracellular fluid concentration, was lowest in the mildly hypercapnic rats at $2 \mathrm{~h}$ of HI. Based on the data, we concluded that during $\mathrm{HI}$ in the immature rat, $\mathrm{CBF}$ is better preserved during normocapnia and mild hypercapnia; the greater oxygen delivery promotes cerebral glucose utilization and oxidative metabolism for optimum maintenance of tissue high-energy phosphate reserves. An inhibition of glutamate secretion into the synaptic cleft and its attenuation of $\mathrm{N}$ methyl-D-aspartate receptor activation would further protect the mildly hypercapnic animal from hypoxic-ischemic brain damage.

Metabolic experiments have yet to be conducted in immature rats undergoing cerebral $\mathrm{HI}$ with superimposed severe hypercapnia. CBF experiments have shown that the lowest blood flow to the vulnerable structures of the immature rat brain during $\mathrm{HI}$ occurs at $\mathrm{CO}_{2}$ tensions approximating $100 \mathrm{~mm}$ $\mathrm{Hg}$. Presumably, this severe degree of hypercapnia is adequate to produce more severe cardiovascular depression than is seen in animals subjected to lesser severities of hypercapnia; the cardiovascular depression, in turn, would lead to greater cerebral ischemia and ultimate brain damage. Cerebral metabolic experiments are required to confirm the existence of greater cerebral ischemia with increasing severities of hypercapnia.

Our past and present experiments in the immature rat pertaining to cerebral $\mathrm{HI}$ at variable $\mathrm{CO}_{2}$ tensions are relevant to the situation in human fetuses and newborn infants. Clinical investigations suggest that premature infants who require mechanical ventilation to prevent or minimize hypoxemia arising from respiratory distress syndrome are at increased risk for the development of periventricular leukomalacia if hypocapnia occurs during the course of respiratory management (2-4). It is assumed that the hypocapnia occurs as a consequence of the hyperventilation necessary to maintain optimal $\mathrm{paO}_{2}$. Mild hypercapnia (permissive hypercapnia) during the course of management of respiratory distress syndrome has recently been advocated (13), but any beneficial effect of mild hypercapnia on the immature human brain has yet to be determined. In fetuses undergoing acute asphyxiation, it is observed that neonates with an umbilical artery $\mathrm{pH}<7.0$ with a prominent respiratory component $\left(\mathrm{pCO}_{2}=12 \mathrm{kPa} ; 92 \mathrm{~mm} \mathrm{Hg}\right)$ are more likely to exhibit neurologic, respiratory, cardiovascular, and gastrointestinal complications than newborn infants with an umbilical artery $\mathrm{pH}>7.24$ (14). With increasing hypercapnia, the proportion of neonates with neurologic complications increases (see Ref. 15). In contrast, Low et al. (16) found that complications in newborns, including encephalopathy, are not increased by respiratory acidosis but rather by a metabolic acidosis (see Ref. 17). Further clinical investigations are required to resolve the issue of the effect of severe hypercapnia on perinatal hypoxic-ischemic brain damage.

\section{REFERENCES}

1. Vannucci RC, Towfighi J, Heitjan DF, Brucklacher RM 1995 Carbon dioxide protects the perinatal brain from hypoxic-ischemic damage: an experimental study in the immature rat. Pediatrics 95:868-874

2. Greisen G, Munch H, Lou H 1987 Severe hypocarbia in preterm infants and neurodevelopmental deficit. Acta Pediatr Scand 86:401-404

3. Graziani L, Spitzer AR, Mitchell DG, Merton DA, Stanley C, Robinson N, McKee L 1992 Mechanical ventilation in preterm infants: neurosonographic and developmental studies. Pediatrics 90:515-522

4. Ikonen RS, Janas MO, Koidikko MJ, Laippala P, Kuusinen EJ 1992 Hyperbilirubinemia, hypocarbia and periventricular leukomalacia in preterm infants. Relationship to cerebral palsy. Acta Pediatr 81:802-807

5. Rice JE, Vannucci RC, Brierley JB 1981 The influence of immaturity on hypoxicischemic brain damage in the rat. Ann Neurol 9:131-141

6. Towfighi J, Yager JY, Housman C, Vannucci RC 1991 Neuropathology of remote hypoxic-ischemic damage in the immature rat. Acta Neuropathol 81:578-587

7. Towfighi J, Housman C, Vannucci RC, Heitjan DF 1994 Effect of unilateral perinatal hypoxic-ischemic brain damage on the gross development of the opposite cerebral hemisphere. Biol Neonate 65:108-118

8. Vannucci RC, Brucklacher RM, Vannucci SJ 1996 The effect of hyperglycemia on cerebral metabolism during hypoxia-ischemia in the immature rat. J Cereb Blood Flow Metab 16:1026-1033

9. Vannucci RC, Duffy TE 1974 The influence of birth on carbohydrate and energy metabolism in rat brain. Am J Physiol 226:933-940

10. Ringel M, Bryan RM, Vannucci RC 1991 Regional cerebral blood flow during hypoxia-ischemia in the immature rat: comparison of iodoantipyrine and iodoamphetamine as radioactive tracers. Dev Brain Res 59:231-235

11. Lyons DT, Vasta F, Vannucci RC 1987 Autoradiographic determination of regional cerebral blood flow in the immature rat. Pediatr Res 21:471-476

12. Vannucci RC, Brucklacher RM, Vannucci SJ 1997 Effect of carbon dioxide on cerebral metabolism during hypoxia-ischemia in the immature rat. Pediatr Res 42:24-29

13. Mariani G, Cifuentes J, Carlo WA 1999 Randomized trial of permissive hypercapnia in preterm infants. Pediatrics 104:1082-1088

14. Van den Berg PP, Nelen WLDM, Jongsma HW, Nijland R, Kollee LAA, Nijhuis JG, Eskes TKAB 1996 Neonatal complications in newborns with an umbilical artery $\mathrm{pH}$ $<7.00$. Am J Obstet Gynecol 175:1152-1157

15. Goodwin TM, Belai I, Hernandez P, Durand M, Paul RH 1992 Asphyxial complications in the term newborn with severe umbilical acidemia. Am J Obstet Gynecol 162:1506-1512

16. Low JA, Panagiotopoulos C, Derrick EJ 1994 Newborn complications after intrapartum asphyxia with metabolic acidosis in the term fetus. Am J Obstet Gynecol 170:1081-1087

17. Low JA, Panagiotopoulos C, Derrick EJ 1995 Newborn complications after intrapartum asphyxia with metabolic acidosis in the preterm fetus. Am J Obstet Gynecol $172: 805-810$ 